\title{
A Welcome From the New Pediatric Exercise Science Editor
}

\author{
Ali McManus \\ The University of British Columbia
}

It is with great pleasure and honour that I assume the responsibilities of Editor-in-Chief of Pediatric Exercise Science from Professor Bareket Falk. Professor Falk served as Editor-in-Chief since 2012, following in the visionary footsteps of the journal's founding editor, Professor Thomas Rowland. Bareket has been an inspiration for the way she has guided Pediatric Exercise Science and her unassuming, yet motivating, leadership of an internationally diverse team of Associate Editors, Board members, and supporting staff from Human Kinetics. As a Board member and Associate Editor, I saw firsthand the passion and sheer hard work Bareket invested in maintaining Pediatric Exercise Science's standing in an increasingly competitive publishing world. As I begin this rather daunting journey at the helm of Pediatric Exercise Science, I will be continually grateful for Bareket's direction and guidance; as I face varying challenges, I will find solace by asking myself, "What would Bareket have done?"

As researchers we live in an ever-evolving scholarly world. A world where journals jostle for podium position in the "high impact" race. Where reviewers are inundated with requests from now countless numbers of scholarly journals. Where researchers are under growing pressure to increase their output of impactful publications. The direction and decisions made by Editors have the power to alter the path of a journal or, equally, change the path of a career in this publish or perish climate. It would be easy to lose sight of the goals and aspirations set out for Pediatric Exercise Science by Professor Rowland in the first edition of the journal in 1989. But the journal has stayed true to these goals, goals that motivated and inspired me throughout my career. As a PhD student in the 1990s I eagerly awaited my copy of Pediatric Exercise Science each quarter. The work published was at the forefront of science for those of us interested in the study of exercise in the child. It became my home, where I read of exciting developments and discoveries in our field, joined the debate when various challenges and controversies emerged, and, importantly, discovered our scientific community, the North American Society for Pediatric Exercise Medicine (NASPEM) and the European Group of Pediatric Work Physiology (PWP).

Pediatric Exercise Science has indeed "pull[ed] together the growing, diverse body of knowledge concerning exercise in children" (1). True to this goal and with a deep sense of responsibility, I am excited by the prospect of serving our scientific community as Editor-in-Chief of Pediatric Exercise Science. As a journal we remain committed to our mission and will continue to communicate outstanding research that advances knowledge of the responses of children, sick and healthy, to exercise; explores the contribution of exercise and physical activity in the treatment and prevention of disease; and the role sport plays in the lives of children.

Ultimately, Pediatric Exercise Science is your journal. Without you, the scientific community, we have no authors, no reviewers, and no readers. I look forward to learning from all of you, so that Pediatric Exercise Science may continue to be your home and to inspire generations of pediatric exercise scientists to come.

Happy New Year to you all!

Ali McManus

\section{Reference}

1. Rowland TW. Welcome to Pediatric Exercise Science! Pediatr Exerc Sci. 1989;1(1):1. doi:10.1123/pes.1.1.1
McManus is the Editor-in-Chief of Pediatric Exercise Science; McManus is a professor of pediatric exercise physiology in the School of Health Sciences, The University of British Columbia, Kelowna, British Columbia, Canada. McManus (ali.mcmanus@ubc.ca) is corresponding author. 